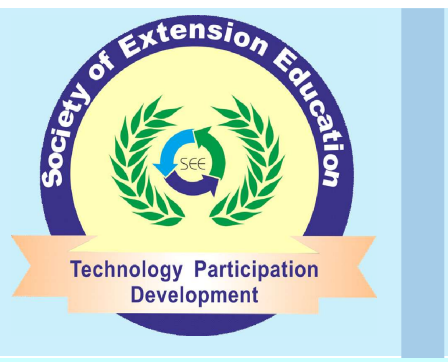

Research Article

\section{Indian Research Journal of Extension Education}

ISSN: 0972-2181 (Print), 0976-1071 (Online)

NAAS Rating : 5.22

Journal homepage: seea.org.in

https://doi.org/10.54986/irjee/2022/jan_mar/24-31

\title{
Using Social Network Analysis to Identify Opinion Leaders in Agricultural Knowledge Exchange and Decision-Making Network of Farm Women
}

\author{
Neelam Basera ${ }^{1}$ and Neelam Bhardwaj ${ }^{2}$ \\ 1. Asstt. Prof. (Agril.. Ext.), Graphic Era Hill University, Dehradun, 2. Prof., G.BPUAT, Pantnagar, Uttarakhand, India \\ Corresponding author e-mail : neelambasera90@gmail.com
}

Paper Received on October 05, 2021, Accepted on December 02, 2021 and Published Online on January 01,2022

\begin{abstract}
The use of social network theories dates back to 1930s with the pioneering works of psycho-sociologist Moreno. With the advent of advanced technologies, there has been an explosion of its applications to various disciplines. The study applies social network theory to analyze agricultural knowledge exchange and decision-making network offarm women. The analysis identifies farm women who occupy central and strategic positions and acts as opinion leaders in the network. The study was carried out in the Himalayan regions of Uttarakhand, India. Descriptive research design and multi-stage sampling were adopted. A total of 298 respondents were selected purposively from the two villages of Uttarakhand. Data were collected through survey sociometric method. UCINET and SPSS were used for data analysis and interpretations. The findings showed that high in degree and Out degree centrality was recorded by $24(12,12)$ and $48(26,22)$ farm women in the two study villages. Total 24 opinion leaders were identified within the agricultural knowledge exchange and decision-making network. Their extent of opinion leadership was influenced by age, marital status, farming experience, socio-economic status, innovativeness, achievement motivation, decision making ability, risk preference, economic motivation, information seeking behaviour, cosmopoliteness and social participation.
\end{abstract}

Key words : Social network analysis; Opinion leaders; Network centrality; Agricultural knowledge exchange.

$\mathbf{W}_{\text {omen are considered to play a critical role in }}$ the dynamic process of social change. Any development effort in this direction requires sensitivity and understanding of women's preferred style of communication and leadership. In Uttarakhand, one of the states in Indian Himalayas, most effective and leading workforce is of women, visible in every walk of life from agriculture to small industry. Women in these regions are responsible for both farm and home management as men have migrated to plain areas in search for better opportunities. But as described by
Jodha (1992), by virtue of certain peculiarities such as fragility, heterogeneity, inaccessibility, non-availability, marginality and diversity of the area, life is tougher for women in the Himalayan regions. Despite women's central role in agriculture, they face numerous challenges in accessing support services offered by the public or private organizations (Karuna, 2013). Evidently, women showed more dependency on interpersonal channels of communication than mass media and other cosmopolite channels of communication (Basera and Bhardwaj, 2018). It is rather the interpersonal channels 
of communication which influences the actions and decisions of others, resulting in patterned flow of communication. As studied by King and Bembridge (1988), it is within these informal networks where key individuals who are often named as opinion leaders or key communicators operates, and acts as the only credible source for knowledge exchange and decisionmaking. Opinion leaders prove to be potential advantage to extension in areas where formal agricultural support system is inadequate. The information diffusion and knowledge exchange by opinion leaders reaches to comparatively more number of farmers and thus, improves farming efficiency, agricultural knowledge exchange and decision-making process as pointed by Bembridge (1986).

Keeping this in view, the study was conducted with primary focus on identifying informal opinion leaders among farm women using network analysis, who may not only enhance the pace of development by ensuring effective extension but can also play a significant role to promote development initiatives at various levels. As stated by Merwe and Heerden (2009) and supported by Borgatti (2006), the identification of opinion leaders can be simplified through the use of social network theories. These networks can be used to construct relational networks, and the individual who are central to these networks can be considered to be the opinion leaders. However, there exists significant difference of opinion leadership even among these opinion leaders. Therefore, the extent to which opinion leadership is exhibited by the identified opinion leaders was measured. The socio-economic, personal, psychological and communication characteristics of identified opinion leaders were studied and their relationship with the extent of opinion leadership was investigated.

Conceptual framework: Network studies are crucial in determining the spread of ideas, information, products and services as well as adoption of new practices and technologies. It was not until the mid-20th century that network analysis was first used as a distinctive methodology of the social sciences and unique feature of social theory. Rogers and Kincaid (1981) conceptualized networks as the regular, work-related, interpersonal patterns that are established between pairs of individuals in social settings. It portrays relationships which reveal the social structures existing within the social system. It can measure the relations between extension agents, farmers and any other intermediaries, which in turn can study the network in relation to improved decision making, knowledge exchange, adoption of better practices and performance which are influenced by the type and sources of information (Muthulakshmi and Singh, 2019).Network analysis provides both a visual and mathematical analysis of human relationships. One of the most frequently used concepts to identify network roles and justify the structural importance of actors in networks is network centrality (Borgatti, 2006; Kim, 2007). Network centrality can be measured in a number of ways based on the purpose of research. The present investigation focuses on degree centrality. Degree centrality is considered as a measure of popularity (prestige) and the actor's immediate influence (Wasserman and Faust, 1994 and Holliday et al., 2016). It equals to the number of ties that a vertex has with another vertex (Yin, et al. 2006). A node with a high degree centrality act as a hub in the network having it a lot of edges coming in and a lot of edges coming out. High degree centrality refers to actors who accesses and spreads information faster than others. Conversely, the person whose index is low can be judged as someone who plays a marginal role in the group.

\section{METHODOLOGY}

The study was conducted in Uttarakhand, a hill state, located in the central part of the Indian Himalayas. The study followed descriptive research design and multi stage sampling procedure for the selection of respondents. Village Badiyakot from Kapkot block of district Bageshwar and village Sabli Talli from Chamba block of district Tehri Garhwal were selected using simple random sampling without replacement. A total of 298 farm women were purposively selected as respondents i.e. 177 respondents from village Badiyakot and 121 respondents from village Sabli Talli and surveyed through personal interview for sociometric responses. The respondents were selected based on following criteria:

i. Farm women who were extensively involved in agriculture and allied activities.

ii. Farm women who were above the age of eighteen years.

The quantitative information was collected through semi-structured interview schedule pre-tested and modified accordingly based on pilot study. Face-to-face 
interaction sessions with the respondents were conducted, sociometric question were asked and sociometric data were collected. Sociometric or "who -to whom" questions was the technique of choice for collecting network data. The data collected were coded, tabulated, analyzed and interpreted with UCINET (6.05) and SPSS. UCINET (Version 6.05) is a Windows software package developed by Steve Borgatti, Martin Everett and Lin Freeman in 2002. It was used for the analysis of network data to calculate degree centrality of respondents. Based on their network (degree) centrality, farm women were categorized under three categories i.e. high, medium and low. Farm women under high categories were identified as respondent with more structural importance and role significance within the network. The agricultural knowledge exchange and decision-making network of farm women was delineated separately for the two sampled villages using network visualization tool, Net Draw.

\section{RESULTS AND DISCUSSION}

Measurement of degree centrality to identify opinion leaders in agricultural knowledge exchange and decision-making network of farm women : In degree centrality: In directed networks, Degree centrality is measured as In degree and Out degree centrality. But to identify opinion leaders, most empirical network studies have focused on finding individuals who have high In degree centrality because it is more likely that people seek advice from individuals who have higher In degree centrality and, therefore, these individuals could affect other people's actions and decision making (Kim et al., 2007). Consequently, opinion leaders were identified as those farm women who belonged to high category of in degree centrality in the two villages. The findings presented in Table 1, concluded that high in degree centrality were recorded by 6.78 per cent of the farm women (12) in Badiyakot village and 9.92 per cent of the farm women (12) in Sabli Talli village. Total twentyfour respondents, twelve from each village and were recognized as opinion leaders based on their high In degree centrality. It was observed that the identified farm women occupy the central position in the network as the holder of influence and dominates the agricultural knowledge exchange and decision-making network of farm women.

Out degree centrality: The findings regarding Out degree centrality of farm women is presented in Table 1. The high Out degree centrality reflects the extent to which 14.69 per cent (26) and 18.18 per cent (22) of farm women in village Badiyakot and Sabli Talli are being influenced by others in the network. Based on observation, it was noted that farm women who reported high Out degree were usually interested in exchanging

Table 1. Distribution of respondents on the basis of their network centrality $(n=298)$

\begin{tabular}{|c|c|c|c|c|c|c|c|c|c|c|c|}
\hline \multicolumn{12}{|c|}{ Degree centrality } \\
\hline \multicolumn{9}{|c|}{ Village Badiyakot $\left(n_{1}=177\right)$} & \multirow{2}{*}{\multicolumn{3}{|c|}{$\begin{array}{c}\text { Village Sabli Talli }\left(n_{2}=121\right) \\
\text { Out degree centrality }\end{array}$}} \\
\hline In degree centr & & & Out degree cen & atrality & & In degree cent & ality & & & & \\
\hline Category & No. & $\%$ & Category & No. & $\%$ & Category & No. & $\%$ & Category & No. & $\%$ \\
\hline $\operatorname{Low}(<1.54)$ & 8 & 4.52 & Low $(<4.55)$ & 20 & 11.30 & Low $(<0.27)$ & 10 & 8.26 & $\operatorname{Low}(<2.83)$ & 9 & 7.44 \\
\hline $\begin{array}{l}\text { Medium } \\
\text { (1.54 to } 14.57 \text { ) }\end{array}$ & 157 & 88.70 & $\begin{array}{l}\text { Medium } \\
(4.55 \text { to } 8.47)\end{array}$ & 131 & 74.01 & $\begin{array}{l}\text { Medium } \\
(0.27 \text { to } 9.92)\end{array}$ & 99 & 81.82 & $\begin{array}{l}\text { Medium } \\
\text { (2.83 to } 6.83 \text { ) }\end{array}$ & 90 & 74.38 \\
\hline $\operatorname{High}(>14.57)$ & 12 & 6.78 & $\operatorname{High}(>8.47)$ & 26 & 14.69 & $\operatorname{High}(>9.92)$ & 12 & 9.92 & $\operatorname{High}(>6.83)$ & 22 & 18.18 \\
\hline
\end{tabular}

Table 2. High network centrality of farm women in the sampled villages

\begin{tabular}{lll}
\hline Network Centrality & Villages & Respondent number with high network centrality in parentheses \\
\hline In degree centrality & Badiyakot & $58(47), 162(44), 129(44), 35(43), 24(40), 146(38), 103(33), 5(32), 71(27), 108(17), 16(17), 119(15)$ \\
& Sabli Talli & $48(29), 61(22), 108(21), 34(19), 24(19), 68(17), 35(17), 13(16), 19(16), 80(15), 113(14), 90(14)$ \\
Out degree centrality & Badiyakot & $65(12), 20(12), 171(11), 94(11), 25(11), 161(10), 121(10) 91(10), 57(10), 42(10), 151(9)$, \\
& & $85(9), 83(9), 59(9), 56(9), 55(9), 52(9), 40(9), 34(9), 29(9), 27(9), 23(9), 22(9), 13(9), 10(9), 8(9)$ \\
& Sabli Talli & $74(12), 75(11), 1(11), 3(9), 76(9), 42(9), 12(8), 79(8), 2(8), 77(8), 11(8), 63(8), 24(8)$, \\
& & $70(7), 19(7), 78(7), 90(7), 69(7), 71(7), 18(7), 55(7), 16(7)$ \\
\hline
\end{tabular}


knowledge with others or bringing awareness to the community. High Out degree centrality of actors as stated by Prell (2011) is an indicator that these actors have the ability to mobilize and diffuse information to larger network and spread information faster than others. Apparently, this is considered as a measure of local or proximate influence in the network. Table 2 represents the respondent number (assigned to farm women) with their corresponding network centrality in the sampled villages.

Figure 1: Network graph based on network centrality of farm women using NetDraw
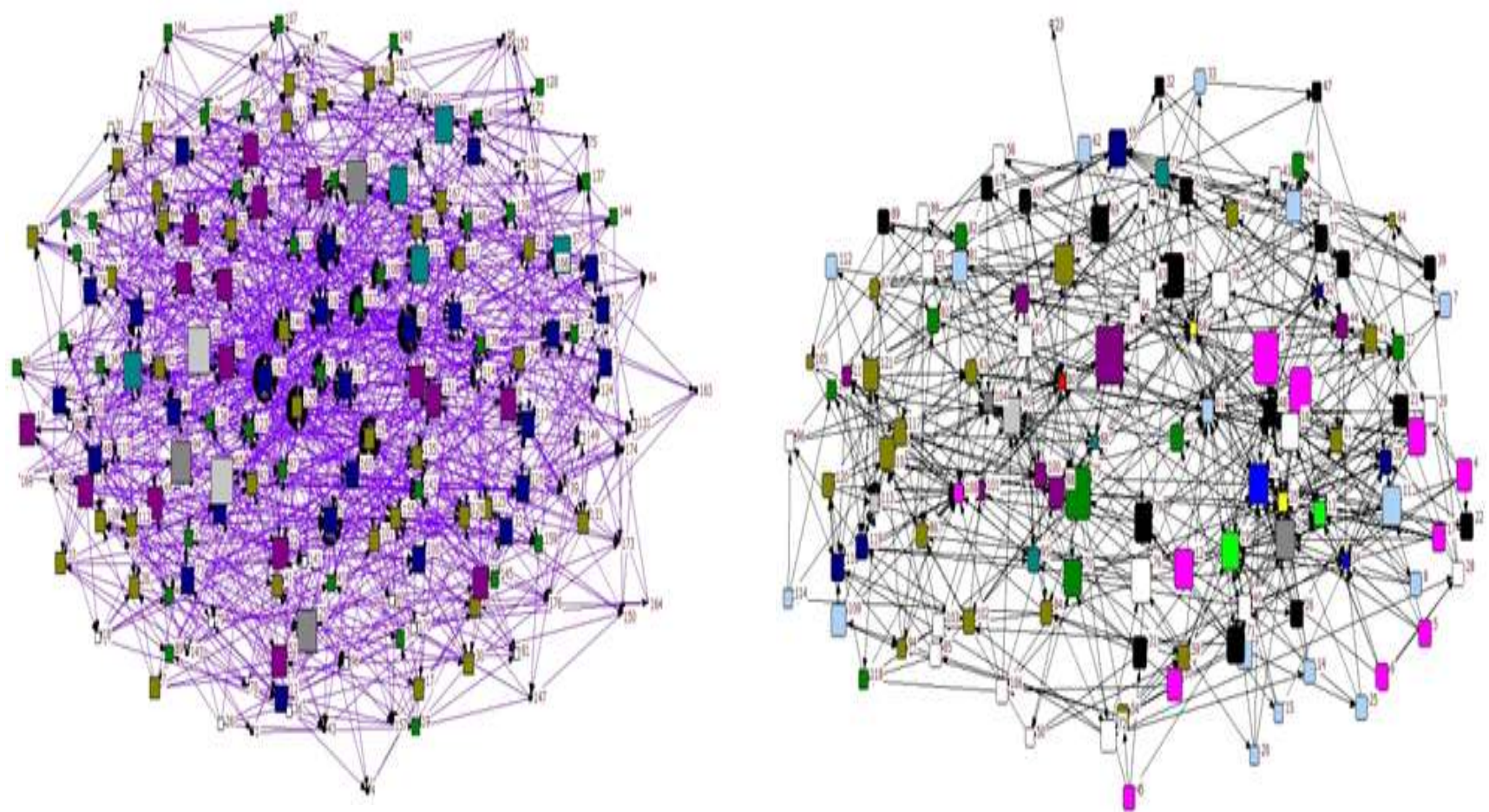

1 (a) Network graph based on In degree centrality in village Badiyakot and Sabli Talli
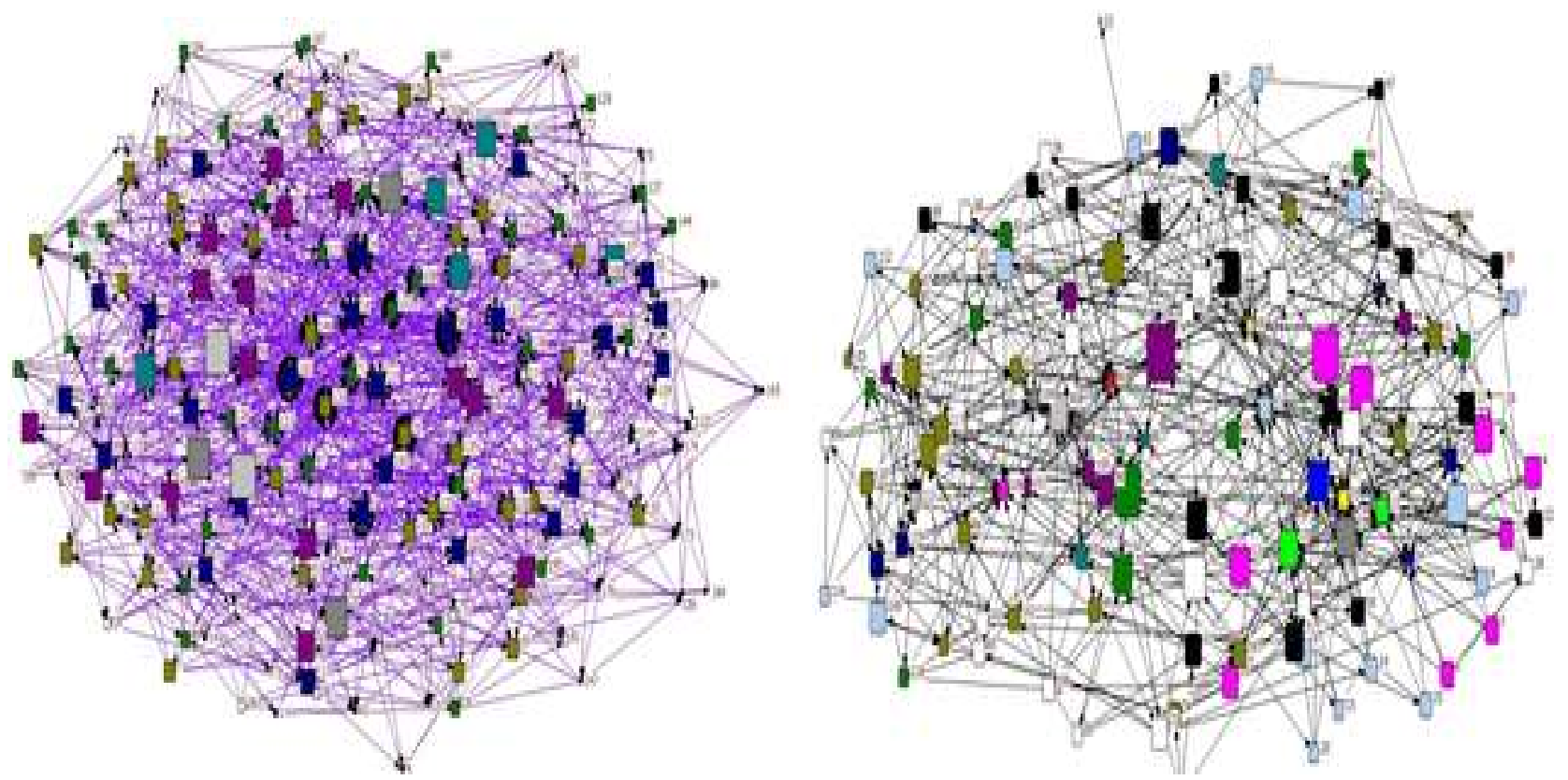

1 (b) Network graph based on Out degree centrality in village Badiyakot and Sabli Talli 
Extent of opinion leadership of the opinion leaders: The dependent variable 'Extent of opinion leadership' was operationalized as the degree to which the opinion leaders are able to influence the agricultural knowledge exchange and decision-making process in the study villages. As stated by Freeman (1979), network centrality reflects importance of individuals based on one's position within network relative to others and may be used to assess opinion leadership. Therefore, for the purpose of measurement of extent of opinion leadership of opinion leaders, In degree centrality was obtained for the opinion leaders on the basis of number of choices from fellow farm women in the village on a sociometric test. It was assumed that the number of people who nominated an individual reflected the amount of influence she has on them. Also, the more nominations one has from other, the higher In degree one has. This means that the lower the number of nominations, the weaker the extent of opinion leadership, while the higher the number of nominations, the stronger the extent of opinion leadership.

Based on the In degree centrality obtained by each opinion leader, opinion leadership was categorized into high, medium and low categories using maximum score (47) minus minimum score (14) divided by three. The data in Table 3 indicates that maximum percentage of the opinion leaders $(58.34 \%$ ) had low opinion leadership followed by 25 per cent of opinion leaders who had high opinion leadership. The remaining 16.66 per cent of the opinion leaders had medium level of extent of opinion leadership. This suggests that opinion leaders differ according to degrees of influence they exert on others in the network.

According to these findings, high opinion leadership was exhibited by one-fourth (25\%) of the opinion leaders and thus, qualified as strong opinion leaders with significant potential influence. The probable reason might be due to the fact that most of these opinion leaders were either more socially active or had maximum years of farming experience. Despite these, the relatively large percentage of opinion leaders about 58.34 per cent indicates low opinion leadership. This implies that many of the influence relationships are within either friendship or relatives' circles/cliques and that these could perhaps be used to effectively mobilize the influence of opinion leaders. Socio-economic, personal, psychological and communication characteristics of opinion leaders : From the data in Table 4, it was observed that majority $(62.40 \%)$ of opinion leaders belonged to middle age category i.e. to the age group of 36 to 52 years, were married $(83.33 \%)$, educated up to primary school (41.67\%), belonged to upper caste $(79.16 \%)$ and had joint family (79.17\%) with 66.66 per cent of opinion leaders having medium family size ( 7 to 10 members). Being a mountainous state, Agriculture was the primary occupation of all the opinion leaders (100\%). About more than half of the opinion leaders i.e. 54.17 per cent performed animal husbandry followed by 20.83 per cent who were engaged in poultry farming as secondary occupation. As regards to farming experience, majority of the opinion leaders $(66.66 \%)$ had medium years of farming experience i.e. between 23 to 39 years. The socio-economic status of women is a critical factor which determines social influence and importance. Table 4 presents the findings indicated in that majority of opinion leaders $(70.84 \%)$ belonged to medium socio-economic status followed by about one-fifth (20.83\%) who belonged to high socio-economic status. Only 8.33 per cent of the opinion leaders were from low socioeconomic status.

The study on psychological and communication characteristics of the opinion leaders, reported that majority of the opinion leaders had medium level of innovativeness (70.84\%), scientific orientation (70.84\%), risk preference $(70.84 \%)$, achievement motivation (75.00\%), decision making ability $(70.84 \%)$ and economic motivation (83.33\%). Medium level of information seeking behavior was shown by majority

Table 3. Extent of opinion leadership among the identified opinion leaders $(\mathrm{N}=24)$

\begin{tabular}{|c|c|c|c|}
\hline Extent of opinion leadership & No. & $\%$ & Respondent No. with corresponding In degree centrality \\
\hline Low opinion leadership (14 to 25 ) & 14 & 58.34 & $\begin{array}{l}16(17), 119(15), 108(17), 35(17), 113(14), 108(21), 34(19), 80(15), \\
19(16), 90(14), 24(19), 68(17), 61(22), 13(16)\end{array}$ \\
\hline Medium opinion leadership (25 to 36 ) & 4 & 16.66 & $5(32), 71(27), 103(33), 48(29)$ \\
\hline High opinion leadership (36 to 47 ) & 6 & 25.00 & $146(38), 58(47), 129(44), 162(44), 24(40), 35(43)$ \\
\hline
\end{tabular}


Table 4. Characteristics of identified opinion leaders $($ Total $=24)$

\begin{tabular}{ll}
\hline Characteristics & No. $\%$ \\
\hline
\end{tabular}

SE and personal characteristics

Age

Young $(<36$ years)

Middle (36-52 years)

Old ( $>52$ years)

Marital Status

Unmarried

Married

Caste

General

$\mathrm{OBC}$

$\mathrm{SC} / \mathrm{ST}$

Education

Can read and write

Primary

Middle

High school

Graduate/ Post graduate

Family Type

Joint

Family size

Small $(<7)$

Medium(7-10)

Large $(>10)$

Farming experience

Low $(<23.37)$

Medium(23.37-38.70)

Socio-economic status

Low $(<92.37)$

Medium(92.37-121.71)

$\operatorname{High}(>121.71)$

Occupation

None

Animal husbandry

Poultry farming

Service

Business

$20 \quad 83.33$

$19 \quad 79.16$

$19 \quad 79.17$

$4 \quad 16.67$

$16 \quad 66.66$

$4 \quad 16.67$

$4 \quad 16.67$

$16 \quad 66.66$

$4 \quad 16.67$
Nuclear

$\operatorname{High}(>38.70)$

Psychological and communication characteristics Innovativeness

Low $(<19.56)$

Medium(19.56-26.02)

$\operatorname{High}(>26.02)$

$3 \quad 12.50$

$17 \quad 70.84$

$4 \quad 16.67$

Achievement Motivation

Low $(<18.90)$

$2 \quad 8.33$

Medium(18.90-27.86)

High (>27.86)

$18 \quad 75.00$

$4 \quad 16.67$

Scientific Orientation

Low $(<16.61)$

Medium(16.61-24.63)

$3 \quad 12.50$

High (>24.63)

$17 \quad 70.84$

$4 \quad 16.67$

Risk Preference

Low $(<16.17)$

Medium(16.17-22.25)

$4 \quad 16.67$

$17 \quad 70.84$

$3 \quad 12.50$

High $(>22.25)$

$4 \quad 16.67$

$17 \quad 70.84$

$3 \quad 12.50$

High (>17.33)

2.50

Economic Motivation

Low $(<18.84)$

Medium(18.84-24.58)

4.17

High $(>24.58)$

83.33

Media Ownership

Low $(<2.03)$

12.50

Medium(2.03-3.73)

41.67

High $(>3.73)$

29.17

Cosmopoliteness

Low $(<4.19)$

Medium(4.19-6.89)

High (>6.89)

Social Participation

Low $(<10.23)$

Medium(10.23-14.69)

High (>14.69)

Information seeking Behaviour

Low $(<24.97) \quad 2 \quad 8.33$

$\begin{array}{lll}\text { Medium(24.97-33.27) } & 17 \quad 70.84\end{array}$

$\operatorname{High}(>33.27)$

$5 \quad 20.83$

$(70.84 \%)$ of the opinion leaders. It was realized that localite source of information were more frequently utilized by opinion leaders as compared to cosmopolite sources, mass media sources and extension education methods. Media ownership was found to be low among maximum percentage i.e. 58.33 per cent of opinion leaders. In terms of cosmopoliteness, maximum number of the respondents (41.67\%) reported medium level of cosmopoliteness. More than half of respondents $(58.33 \%)$ had medium level of social participation. 
Relationship between dependent and independent variables under the study: Coefficient of correlation was computed using Statistical Package for Social Sciences (SPSS, 2007). To explore the relationships, Pearson's product moment correlation co-efficient (r) has been used to test the hypotheses concerning the relationships between the independent and dependent variables. The data in Table 5 shows the relationship between the socio-economic, personal, and psychological and communication characteristics of the opinion leaders with their extent of opinion leadership.

Based on the analysis, it was also noted that age, marital status, farming experience, socio-economic status, innovativeness, achievement motivation, decision making ability, risk preference, economic motivation, information seeking behaviour, cosmopoliteness and social participation were positively and significantly related to the dependent variable i.e. extent of opinion leadership. Age, marital status, farming experience and risk preference were significant at $5 \%$ level of significance whereas the remaining variables (socioeconomic status, innovativeness, achievement motivation, decision making ability, economic motivation, information seeking behaviour, cosmopoliteness and social participation) were significant at $1 \%$ level of significance respectively. Caste, farm size, family type, occupation, scientific orientation and media ownership of opinion leaders had positive and non-significant relationship with the extent of opinion leadership. However, contrary to most of the studies, it was observed that educational status of opinion leaders had negative and non-significant relationship with the extent of opinion leadership.

\section{CONCLUSION}

Based on degree centrality, twenty-four opinion leaders were identified within the agricultural knowledge exchange and decision-making network. High In degree and Out degree centrality was recorded by 24 and 48 farm women. Majority of opinion leaders were married $(83.33 \%)$, educated up to primary school $(41.67 \%)$, belonged to upper caste $(79.16 \%)$, medium socioeconomic status (70.84\%), joint family $(79.17 \%)$ with medium family size (7-10 members) and were in the age group of 36 to 52 years (62.40\%). Media ownership was low among opinion leaders $(58.33 \%)$. While majority
Table 5. Correlation between dependent and independent variables under study

\begin{tabular}{lll}
\hline Variables & "r" & " $\rho "$ \\
\hline Age & $0.429^{*}$ & 0.037 \\
Caste & $0.005^{\mathrm{NS}}$ & 0.982 \\
Marital Status & $0.436^{*}$ & 0.033 \\
Education & $-0.356^{\mathrm{NS}}$ & 0.088 \\
Family Size & $0.326^{\mathrm{NS}}$ & 0.120 \\
Family Type & $0.113^{\mathrm{NS}}$ & 0.599 \\
Occupation & $0.255^{\mathrm{NS}}$ & 0.229 \\
Farming Experience & $0.411^{*}$ & 0.046 \\
Socio-economic status & $0.600^{* *}$ & 0.002 \\
Innovativeness & $0.826^{* *}$ & 0.000 \\
Achievement Motivation & $0.756^{* *}$ & 0.000 \\
Scientific Orientation & $0.247^{\mathrm{NS}}$ & 0.245 \\
Decision Making Ability & $0.552^{* *}$ & 0.005 \\
Risk Preference & $0.476^{*}$ & 0.019 \\
Economic Motivation & $0.614^{* *}$ & 0.001 \\
Media Ownership & $0.076^{\mathrm{NS}}$ & 0.724 \\
Information seeking Behaviour & $0.711^{* *}$ & 0.000 \\
Cosmopoliteness & $0.638^{* *}$ & 0.001 \\
Social Participation & $0.671^{* *}$ & 0.000 \\
\hline NS: Non Signficant & &
\end{tabular}

NS: Non Significant

* Correlation is significant at the 0.05 level (2-tailed).

** Correlation is significant at the 0.01 level (2-tailed).

of the opinion leaders had medium level of innovativeness (70.84\%), scientific orientation (70.84\%), risk preference $(70.84 \%)$, achievement motivation $(75.00 \%)$, decision making ability $(70.84 \%)$, economic motivation (83.33\%), cosmopoliteness (41.67\%), social participation (58.33\%) and information seeking behavior (70.84\%). Strong opinion leadership was exhibited by only six. Extent of opinion leadership was influenced by age, marital status, farming experience, socio-economic status, innovativeness, achievement motivation, decision making ability, risk preference, economic motivation, information seeking behaviour, cosmopoliteness and social participation.

\section{ACKNOWLEDGEMENT}

I am grateful to UGC for providing financial support (UGC NET JRF) which was of immense help in conducting the research.

\section{CONFLICTS OF INTEREST}

The authors declare that they have no conflicts of interest. 


\section{REFERENCES}

Basera, N. and Bhardwaj, N. (2018). Effectiveness of low-cost communication package on enhancing awareness on entrepreneurial skills of women in Uttarakhand. Indian Res.J.Ext. Edu., 18 (4):12-17.

Bembridge, T. J. (1986). An overview of agricultural and rural development problems in less developed areas of Southern Africa. Devel. Southern Africa. 3(1): 20-36.

Borgatti, S. P. (2006). Identifying sets of key players in a social network. Computational. Mathematical and Organizational Theory. 12: 21-34.

Freeman, L. C. (1979). Centrality in social networks: Conceptual clarification. Social Networks. 1(3): 215-239.

Holliday, J., Audrey, S., Campbell, R., and Moore, L. (2016). Identifying well-connected opinion leaders for informal health promotion: The example of the ASSIST smoking prevention program. Health Communication. 31(8): 946-953

Jodha, N. S. (1992). Mountain perspective and sustainability: A framework for development strategies en sustainable mountain agricultures Vol II New Delhi, ICIMOD Oxford Publ.

Karuna. (2013). Water and forest resource management practices followed by hill women: A study in nainital district of Uttarakhand. Thesis, Ph.D., G. B. Pant University of Agriculture and Technology, Pantnagar.

Kim, D. (2007). Identifying Opinion Leaders by using Social Network Analysis: A synthesis of opinion leadership data collection methods and instruments. Thesis, Ph.D. Ohio University. Athens, Ohio, United States.

Kim, D. K., Chitnis, K., Vasanti, P. N. and Singhal, A. (2007). Opinion leadership networks and diffusion of e-choupal in Indian villages. J. of Creative Commu., 2(3): 345-360.

King, P. G. and Bembridge, T. J. (1988). An extension approach for the national grazing strategy based on farmer characteristics in the Eastern Cape. J. of the Grassland Society of Southern Africa, 5 (1): 8-14.

Merwe, R. V. D. and Heerden, G. V. (2009). Finding and utilizing opinion leaders: Social networks and the power of relationships. South African J. of Busi. Management, 40(3): 65-75.

Muthulakshmi, B. and Singh, R.J. (2019). social networks of farmers on climate change mitigation and adaptation in western agro climatic zone of Tamil Nadu. Indian Res.J.Ext. Edu., 19 (1):43-48.

Prell, C. (2011). Social network analysis: History, theory and methodology. London: SAGE Publications.

Rogers, E. M. and Kincaid, D. L. (1981). Communication networks: Toward a new paradigm for research, The Free Press, New York. pp. 31-78.

SPSS. (2007). Statistical packages for social sciences. Ver. 126, SPSS Inc., llinois, USA

Wasserman, S. and Faust, K. (1994). Social network analysis: Methods and applications, Cambridge University Press, Cambridge.

Yin, L., Kretschmer, H., Hanneman, R. A. and Liu, Z. (2006). Connection and stratification in research collaboration: An analysis of the COLLNET network. Info. Proc. and Management. 42: 1599- 1613. 